\title{
Pharmacokinetic/pharmacodynamic analysis of teicoplanin in patients with MRSA infections
}

This article was published in the following Dove Press journal:

Clinical Pharmacology:Advances and Applications

30 March 2016

Number of times this article has been viewed

\section{Kazuaki Matsumoto' \\ Erika Watanabe \\ Naoko Kanazawa' \\ Tomohide Fukamizu' \\ Akari Shigemi' \\ Yuta Yokoyama ${ }^{1,2}$ \\ Kazuro Ikawa ${ }^{2}$ \\ Norifumi Morikawa \\ Yasuo Takeda' \\ 'Department of Clinical Pharmacy and Pharmacology, Graduate School of Medical and Dental Sciences, Kagoshima University, Kagoshima, ${ }^{2}$ Department of Clinical Pharmacotherapy, Hiroshima University, Hiroshima, Japan}

Correspondence: Yasuo Takeda Department of Clinical Pharmacy and Pharmacology, Graduate School of Medical and Dental Sciences, Kagoshima University, 8-35-I Sakuragaoka,

Kagoshima 890-8520, Japan

$\mathrm{Tel}+8 \mathrm{I} 992755543$

Fax +8 I 992655293

Email takeda@m.kufm.kagoshima-u.ac.jp
Background: Teicoplanin is a glycopeptide antibiotic that has been used to treat serious, invasive infections caused by Gram-positive bacteria. The area under the drug concentrationtime curve (AUC)/minimum inhibitory concentration (MIC) was identified as a pharmacokinetic-pharmacodynamic (PK-PD) parameter of glycopeptide antibiotics that correlated with bacteriological responses and clinical outcomes. Although optimized dosing regimens based on PK-PD are needed, a PK-PD analysis of teicoplanin against methicillin-resistant Staphylococcus aureus (MRSA) infections has not yet been performed. Thus, this study examined patients with MRSA infections, who were administered with teicoplanin in order to determine the target AUC/MIC ratio.

Methods: This study retrospectively assessed data obtained as part of our routine therapeutic drug monitoring (TDM) of teicoplanin therapy in 46 patients with MRSA infections at Kagoshima University Hospital. Serum concentrations of teicoplanin were determined using a fluorescence polarization immunoassay system and used for a Bayesian PK estimation to estimate AUC for 24 hours $\left(\mathrm{AUC}_{24}\right)$. The MIC value for teicoplanin was determined using a standardized agar dilution method. The effects of teicoplanin were evaluated in terms of bacteriological responses by a quantitative assessment.

Results: The estimated $\mathrm{AUC}_{24} / \mathrm{MIC}$ ratios with and without bacteriological responses were 926.6 $\pm 425.2 \mu \mathrm{g} \cdot \mathrm{h} / \mathrm{mL}(\mathrm{n}=34)$ and $642.2 \pm 193.9 \mu \mathrm{g} \cdot \mathrm{h} / \mathrm{mL}$, respectively $(\mathrm{n}=12 ; P<0.05)$. On the basis of a logistic regression analysis, $\mathrm{AUC}_{24} / \mathrm{MIC}$ ratios of $500 \mu \mathrm{g} \cdot \mathrm{h} / \mathrm{mL}, 700 \mu \mathrm{g} \cdot \mathrm{h} / \mathrm{mL}$, and $900 \mu \mathrm{g} \cdot \mathrm{h} / \mathrm{mL}$ gave probabilities of treatment success of $0.50,0.72$, and 0.87 , respectively. Furthermore, using the Kaplan-Meier curve analysis, an $\mathrm{AUC}_{24} / \mathrm{MIC}$ ratio of $\geq 900$ led to a significantly stronger bacteriological response than an $\mathrm{AUC}_{24} / \mathrm{MIC}$ ratio of $<900$.

Conclusion: These results suggest that an $\mathrm{AUC}_{24} / \mathrm{MIC}$ ratio of $\geq 900 \mu \mathrm{g} \cdot \mathrm{h} / \mathrm{mL}$ is required to ensure a sufficient bacteriological response.

Keywords: teicoplanin, PK/PD, AUC/MIC, MRSA

\section{Introduction}

There has been an increasing interest in pharmacokinetic (PK)/pharmacodynamic (PD) analyses because they are able to optimize dosing regimens, thereby improving outcomes. ${ }^{1} \mathrm{PK} / \mathrm{PD}$ analyses, based on the principle reported by $\mathrm{Craig}^{2}$ and other researchers to optimize dose regimens for clinical applications, are now increasing in the USA and Europe. Teicoplanin is a glycopeptide antibiotic that has been used to treat serious, invasive infections caused by Gram-positive bacteria. ${ }^{3}$ The area under the drug concentration-time curve (AUC)/minimum inhibitory concentration (MIC) has been identified as a PK/PD parameter of glycopeptide antibiotics that correlated 
with bacteriological responses and clinical outcomes. ${ }^{4,5}$ The guidelines for therapeutic drug monitoring of vancomycin suggest that an AUC/MIC ratio of $\geq 400$ is the $\mathrm{PK} / \mathrm{PD}$ parameter associated with clinical and bacteriological responses to vancomycin therapy. ${ }^{6,7}$ Although optimized dosing regimens based on PK/PD are needed, the PK/PD analysis of teicoplanin against methicillin-resistant Staphylococcus aureus (MRSA) infections has not yet been performed. Therefore, the target AUC/MIC ratio of teicoplanin remains unclear. We herein examined patients with MRSA infections who were administered with teicoplanin in order to determine the target AUC/MIC ratio of teicoplanin.

\section{Methods}

\section{Patients}

The number of beds at Kagoshima University Hospital is 715. This study retrospectively assessed data obtained as part of our routine TDM of teicoplanin therapy in 46 patients with MRSA infections at Kagoshima University Hospital. This study was approved by the Ethics Review Board of Kagoshima University Hospital (\#273).

Patients were excluded if they fulfilled any of the following criteria: children, lack of TDM data, teicoplanin MIC data for MRSA and culture test data, and combination with other anti-MRSA agents.

Teicoplanin was administered intravenously at an initial dose of $200 \mathrm{mg}(\mathrm{n}=4), 400 \mathrm{mg}(\mathrm{n}=30), 500 \mathrm{mg}(\mathrm{n}=2), 600 \mathrm{mg}$ $(\mathrm{n}=8)$, and $800 \mathrm{mg}(\mathrm{n}=2)$ every 12 hours for three doses. Then, teicoplanin was continued at a maintenance dose of $200 \mathrm{mg}$ $(\mathrm{n}=14), 300 \mathrm{mg}(\mathrm{n}=3), 400 \mathrm{mg}(\mathrm{n}=22), 500 \mathrm{mg}(\mathrm{n}=1), 600 \mathrm{mg}$ $(\mathrm{n}=5)$, and $800 \mathrm{mg}(\mathrm{n}=1)$ every 24 hours.

\section{Measurement of teicoplanin trough concentrations}

Serum samples were separated from venous blood by centrifugation at 3,000 rpm for 10 minutes, and serum concentrations of teicoplanin were determined by using a fluorescence polarization immunoassay system (TDxFLx analyzer; Abbott Laboratories, Abbott Park, IL, USA).

\section{Creatinine clearance}

Creatinine clearance $\left(\mathrm{CL}_{\mathrm{cr}}\right)$ was estimated using the actual body weight value in the Cockcroft-Gault formula. ${ }^{8}$

\section{Estimation of AUC for 24 hours}

The serum teicoplanin concentration in each patient was used to estimate individual total clearance $\left(\mathrm{CL}_{\text {total }}\right)$ by using a Bayesian estimation based on the population PK parameters of teicoplanin in the Japanese patients. ${ }^{9}$ The mean population
PK parameters were as follows: teicoplanin clearance $(\mathrm{L} / \mathrm{h})=0.00498 \times \mathrm{CL}_{\mathrm{cr}}(\mathrm{mL} / \mathrm{min})+0.00426 \times$ body weight $(\mathrm{kg})$; the distribution volume of the central compartment (L) $=10.4$; the transfer rate constant from the central compartment to the peripheral compartment $\left(\mathrm{h}^{-1}\right)=0.38$; the transfer rate constant from the peripheral compartment to the central compartment $\left(\mathrm{h}^{-1}\right)=0.0485$. The AUC value for 24 hours under steady-state conditions was estimated as AUC for 24 hours $\left(\mathrm{AUC}_{24} ; \mu \mathrm{g} \cdot \mathrm{h} / \mathrm{mL}\right)=$ daily dose $(\mathrm{mg}) / \mathrm{CL}_{\text {total }}(\mathrm{L} / \mathrm{h}){ }^{4}$

\section{Teicoplanin susceptibility testing}

The MIC for teicoplanin was determined using the standardized agar dilution method according to the Clinical and Laboratory Standards Institute guidelines. ${ }^{10}$ A suspension of bacteria equivalent to the $0.5 \mathrm{McF}$ arland turbidity standards was inoculated onto Mueller-Hinton agar plates. An E-test for teicoplanin was plated onto the agar. The MIC value was read following $16-20$ hours of incubation at $37^{\circ} \mathrm{C}$.

\section{Bacteriological efficacy}

The effects of teicoplanin in terms of bacteriological responses were evaluated with a quantitative and/or semiquantitative assessment. The detected MRSA strains were sorted into five levels according to bacterial counts. "Eradication" was defined when bacterial count was zero, "decrease" when bacterial count was decreased by 1-4 levels, and "persistent" when bacterial count remained unchanged or increased. The teicoplanin treatment was then classified as "success" (eradication and a decrease in MRSA) or "failure" (persistent MRSA).

\section{Statistical analysis}

A logistic regression analysis was performed to determine whether the teicoplanin $\mathrm{AUC}_{24} / \mathrm{MIC}$ ratio was a significant predictor of bacteriological responses (1, success; 0 , failure). The time from initiation of the teicoplanin treatment to the development of microbiological efficacy was estimated using a Kaplan-Meier curve analysis. All statistical analyses were performed using SPSS software (Version 15.0J; SPSS Inc., Chicago, IL, USA).

\section{Results}

Patient characteristics are shown in Table 1. A total of 46 patients, 36 men and ten women, with a mean age of $73.1 \pm 9.4$ years and body weight of $53.5 \pm 10.8 \mathrm{~kg}$, were available for retrospective analysis. The indications for teicoplanin treatment were as follows: wound infection $(n=17)$, pneumonia $(n=14)$, bacteremia $(n=6)$, and others $(n=9)$. The MICs and their percentages of strains were $0.38 \mu \mathrm{g} / \mathrm{mL}$ 
Table I Characteristics of 46 patients included in the present study

\begin{tabular}{ll}
\hline Characteristics & Number or mean \pm SD (range) \\
\hline Sex & 36 \\
Male & 10 \\
Female & $73.1 \pm 9.4(53-86)$ \\
Age (years) & $53.5 \pm 10.8(36.0-77.5)$ \\
Body weight (kg) & 17 \\
Clinical situation & 14 \\
Wound infection & 6 \\
Pneumonia & 9 \\
Bacteremia & Others
\end{tabular}

Abbreviation: SD, standard deviation.

(2.2\%), $0.5 \mu \mathrm{g} / \mathrm{mL}$ (6.5\%), $0.75 \mu \mathrm{g} / \mathrm{mL}$ (43.5\%), $1.0 \mu \mathrm{g} / \mathrm{mL}$ (34.8\%), and $1.5 \mu \mathrm{g} / \mathrm{mL}(13.0 \%)$.

The $\mathrm{AUC}_{24} / \mathrm{MIC}$ ratios with and without bacteriological responses were $926.6 \pm 425.2 \mu \mathrm{g} \cdot \mathrm{h} / \mathrm{mL}(\mathrm{n}=34)$ and $642.2 \pm 193.9 \mu \mathrm{g} \cdot \mathrm{h} / \mathrm{mL}(\mathrm{n}=12)(P<0.05)$, respectively. Figure 1 shows the relationship between $\mathrm{AUC}_{24} / \mathrm{MIC}$ ratios on day 3 and bacteriological responses (failure, 0; success, 1). $\mathrm{AUC}_{24} / \mathrm{MIC}$ ratios of 500,700 , and $900 \mu \mathrm{g} \cdot \mathrm{h} / \mathrm{mL}$ gave probabilities of treatment success of $0.50,0.72$, and 0.87 , respectively.

The bacteriological treatment successes were evaluated in 15 patients with $\mathrm{AUC}_{24} / \mathrm{MIC}$ ratios of $\geq 900$ and 31 patients with $\mathrm{AUC}_{24} / \mathrm{MIC}$ ratios of $<900$ using the Kaplan-Meier curve analysis (Figure 2). Patients with $\mathrm{AUC}_{24} / \mathrm{MIC}$ ratios of $\geq 900$ had significantly stronger bacteriological responses than those with $\mathrm{AUC}_{24} / \mathrm{MIC}$ ratios of $<900(P<0.05)$.

\section{Discussion}

For vancomycin, trough concentrations are used as a surrogate of AUC values. The trough concentrations of $10-20 \mu \mathrm{g} / \mathrm{mL}$

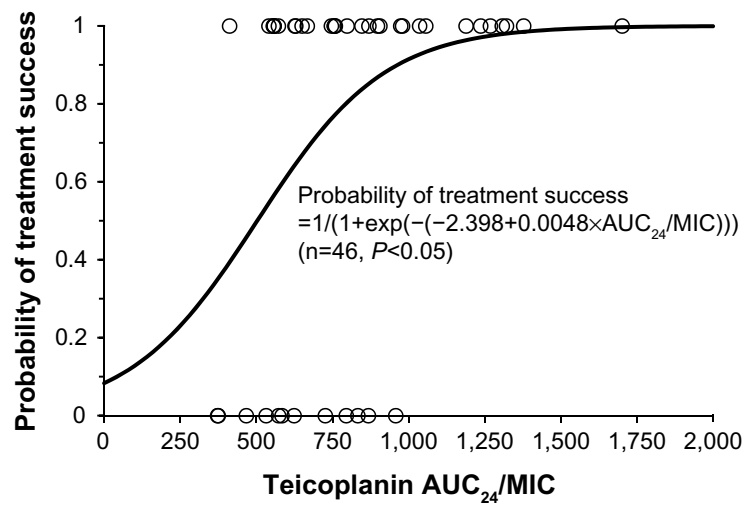

Figure I Teicoplanin $\mathrm{AUC}_{24} / \mathrm{MIC}$ ratio and logistic regression model for bacteriological responses (failure, 0 ; success, I).

Abbreviations: $\mathrm{AUC}_{24}$, area under the concentration-time curve for 24 hours; MIC, minimum inhibitory concentration.

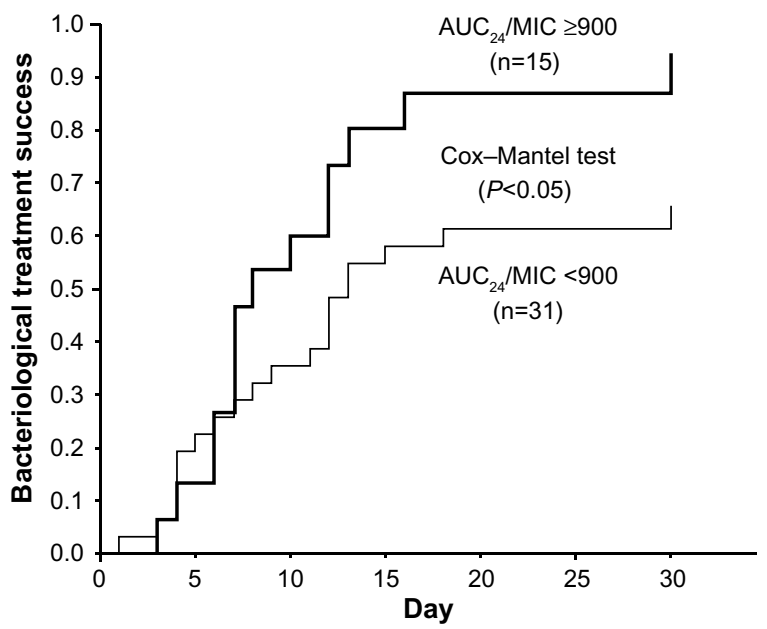

Figure 2 Kaplan-Meier plot showing the time from the initiation of teicoplanin therapy to efficacy rates between the $\mathrm{AUC}_{24} / \mathrm{MIC}$ ratios of $\geq 900(n=15)$ and $<900$ $(n=3 I)$.

Abbreviations: $\mathrm{AUC}_{24}$, area under the concentration-time curve for 24 hours; MIC, minimum inhibitory concentration.

are needed to achieve an AUC value of $\geq 400 .{ }^{6}$ If an $\mathrm{AUC} /$ MIC ratio of $\geq 400$ is not achieved, even though an appropriate trough level is achieved, vancomycin treatment would not exhibit a good response. Similar to teicoplanin, previous studies have shown that teicoplanin trough concentrations of $>13 \mu \mathrm{g} / \mathrm{mL}$ are effective for treating most infections. ${ }^{11}$ However, the teicoplanin treatment should be optimized using AUC/MIC ratios on the basis of PK/PD. Thus, this study examined patients with MRSA infections who were administered with teicoplanin in order to determine the target AUC/ MIC ratio of teicoplanin. This PK/PD analysis determined the $\mathrm{AUC}_{24} / \mathrm{MIC}$ target value of teicoplanin required to cure patients with MRSA infections. The $\mathrm{AUC}_{24} / \mathrm{MIC}$ ratios of 500,700 , and $900 \mu \mathrm{g} \cdot \mathrm{h} / \mathrm{mL}$ showed probabilities of treatment success of $0.50,0.72$, and 0.87 , respectively.

Craig previously reported that AUC/MIC ratios may be an important $\mathrm{PK} / \mathrm{PD}$ parameter that correlates with the efficacy of vancomycin and teicoplanin. ${ }^{5}$ Hagihara et al reported that the $\mathrm{AUC}_{24}$ value on the third day was significantly higher in the treatment success group $(897.6 \pm 71.7 \mu \mathrm{g} \cdot \mathrm{h} / \mathrm{mL})$ than that of the treatment failure group $(652.9 \pm 83.4 \mu \mathrm{g} \cdot \mathrm{h} / \mathrm{mL}) .{ }^{12}$ These findings indicated that an $\mathrm{AUC}_{24}$ value of at least $800 \mu \mathrm{g} \cdot \mathrm{h} / \mathrm{mL}$ is required to ensure bacteriological responses (MIC of $\leq 1.0 \mu \mathrm{g} / \mathrm{mL}$ for all isolates). ${ }^{12}$ Kanazawa et al also showed that an increase in the probability of treatment success was dependent on $\mathrm{AUC}_{24}$ values and that the target that gave a probability of $\sim 0.9$ was $750 \mu \mathrm{g} \cdot \mathrm{h} / \mathrm{mL}$ (MIC of $<2.0 \mu \mathrm{g} / \mathrm{mL}$ for all isolates). ${ }^{13}$ They could not estimate $\mathrm{AUC}_{24} / \mathrm{MIC}$, because exact MICs were not measured. On the other hand, Ogawa et al indicated that a $\log \left[C_{\max , \text { unbound }} / \mathrm{MIC}\right]$ of 0.30 on day 3 of 
teicoplanin therapy was the threshold for achieving treatment success ${ }^{14}$; however, they did not evaluate $\mathrm{AUC}_{24} / \mathrm{MIC}$ ratios. The MICs of teicoplanin for a total of 46 MRSA strains were determined in the present study by the $E$-test method. $\mathrm{AUC}_{24} / \mathrm{MIC}$ ratios were significantly higher in the treatment success group $(926.6 \pm 425.2 \mu \mathrm{g} \cdot \mathrm{h} / \mathrm{mL})$ than in the treatment failure group (642.2 \pm 193.9$)$. An $\mathrm{AUC}_{24} / \mathrm{MIC}$ ratio of $900 \mu \mathrm{g} \cdot \mathrm{h} / \mathrm{mL}$ showed a probability of treatment success of 0.87 (Figure 1). Furthermore, using the Kaplan-Meier curve analysis, an $\mathrm{AUC}_{24} / \mathrm{MIC}$ ratio of $\geq 900$ exhibited a significantly stronger bacteriological response than that of an $\mathrm{AUC}_{24} / \mathrm{MIC}$ ratio of $<900$ (Figure 2). These results suggested that an $\mathrm{AUC}_{24} / \mathrm{MIC}$ ratio of $\geq 900 \mu \mathrm{g} \cdot \mathrm{h} / \mathrm{mL}$ may be required to ensure bacteriological responses. Therefore, not only trough concentrations but also AUC/MIC ratios should be monitored for teicoplanin TDM.

This study focused on bacteriological responses because clinical outcomes, such as relief from symptoms, reduced white blood cell count, and decrease in body temperature, are dependent on many factors. ${ }^{12,13,15}$ However, clinical outcomes are also important for the interpretation and clinical applicability of the current results. Additionally, in this retrospective study, each patient was different in teicoplanin dose, duration of therapy, severity of illness, and type of infections. Therefore, well-designed prospective studies for various types of infection in a larger number of patients are needed to validate the current findings.

\section{Conclusion}

This $\mathrm{PK} / \mathrm{PD}$ analysis revealed the target $\mathrm{AUC}_{24} / \mathrm{MIC}$ ratios of teicoplanin in patients with MRSA infections on the basis of $\mathrm{PK} / \mathrm{PD}$ analyses. These results indicated that an $\mathrm{AUC}_{24} / \mathrm{MIC}$ ratio of $\geq 900 \mu \mathrm{g} \cdot \mathrm{h} / \mathrm{mL}$ is required to ensure bacteriological responses. However, further studies are needed to confirm these results and clarify their therapeutic implications.

\section{Disclosure}

The authors report no conflicts of interest in this work.

\section{References}

1. Scaglione F. Can PK/PD be used in everyday clinical practice. Int $J$ Antimicrob Agents. 2002;19:349-353.
2. Craig WA. Pharmacokinetic/pharmacodynamic parameters: rationale for antibacterial dosing of mice and men. Clin Infect Dis. 1998; 26:1-10.

3. Wilson AP, Grüneberg RN, Neu H. A critical review of the dosage of teicoplanin in Europe and the USA. Int J Antimicrob Agents. 1994;4 (Suppl 1):1-30.

4. Kuti JL, Kiffer CR, Mendes CM, Nicolau DP. Pharmacodynamic comparison of linezolid, teicoplanin and vancomycin against clinical isolates of Staphylococcus aureus and coagulase-negative staphylococci collected from hospitals in Brazil. Clin Microbiol Infect. 2008; $14: 116-123$

5. Craig WA. Basic pharmacodynamics of antibacterials with clinical applications to the use of beta-lactams, glycopeptides, and linezolid. Infect Dis Clin North Am. 2003;17:479-501.

6. Matsumoto K, Takesue Y, Ohmagari N, et al. Practice guidelines for therapeutic drug monitoring of vancomycin: a consensus review of the Japanese Society of Chemotherapy and the Japanese Society of Therapeutic Drug Monitoring. J Infect Chemother. 2013;19: 365-380.

7. Rybak M, Lomaestro B, Rotschafer JC, et al. Therapeutic monitoring of vancomycin in adult patients: a consensus review of the American Society of Health-System Pharmacists, the Infectious Diseases Society of America, and the Society of Infectious Diseases Pharmacists. Am J Health Syst Pharm. 2009;66:82-98.

8. Cockcroft DW, Gault MH. Prediction of creatinine clearance from serum creatinine. Nephron. 1976;16:31-41.

9. Nakayama K, Gemma H, Kaibara A, Niwa T. Population pharmacokinetics of teicoplanin in adult patients. Jpn J Chemother. 2006;54:1-6.

10. Wikler MA, Hindler JF, Cockerill FR, et al. Methods for Dilution Antimicrobial Susceptibility Tests for Bacteria that Grow Aerobically; Approved Standard. 8th ed. Clinical and Laboratory Standards Institute; Wayne, PA, USA, 2009. Document M7-A8.

11. Matsumoto K, Kanazawa N, Ikawa K, et al. Determination of teicoplanin trough concentration target and appropriate total dose during the first 3 days: a retrospective study in patients with MRSA infections. $J$ Infect Chemother. 2010;16:193-199.

12. Hagihara M, Umemura T, Kimura M, Mori T, Hasegawa T, Mikamo H. Exploration of optimal teicoplanin dosage based on pharmacokinetic parameters for the treatment of intensive care unit patients infected with methicillin-resistant Staphylococcus aureus. J Infect Chemother. 2012;18:10-16.

13. Kanazawa N, Matsumoto K, Ikawa K, et al. An initial dosing method for teicoplanin based on the area under the serum concentration time curve required for MRSA eradication. J Infect Chemother. 2011; 17:297-300.

14. Ogawa R, Kobayashi S, Sasaki Y, Makimura M, Echizen H. Population pharmacokinetic and pharmacodynamic analyses of teicoplanin in Japanese patients with systemic MRSA infection. Int J Clin Pharmacol Ther. 2013;51:357-366.

15. Tam VH, McKinnon PS, Akins RL, Rybak MJ, Drusano GL. Pharmacodynamics of cefepime in patients with Gram-negative infections. J Antimicrob Chemother. 2002;50:425-428.
Clinical Pharmacology: Advances and Applications

\section{Publish your work in this journal}

Clinical Pharmacology: Advances and Applications is an international, peer-reviewed, open access journal publishing original research, reports, reviews and commentaries on all areas of drug experience in humans. The manuscript management system is completely online and includes a very quick and fair peer-review system, which is all easy to use.

\section{Dovepress}

Visit http://www.dovepress.com/testimonials.php to read real quotes from published authors. 